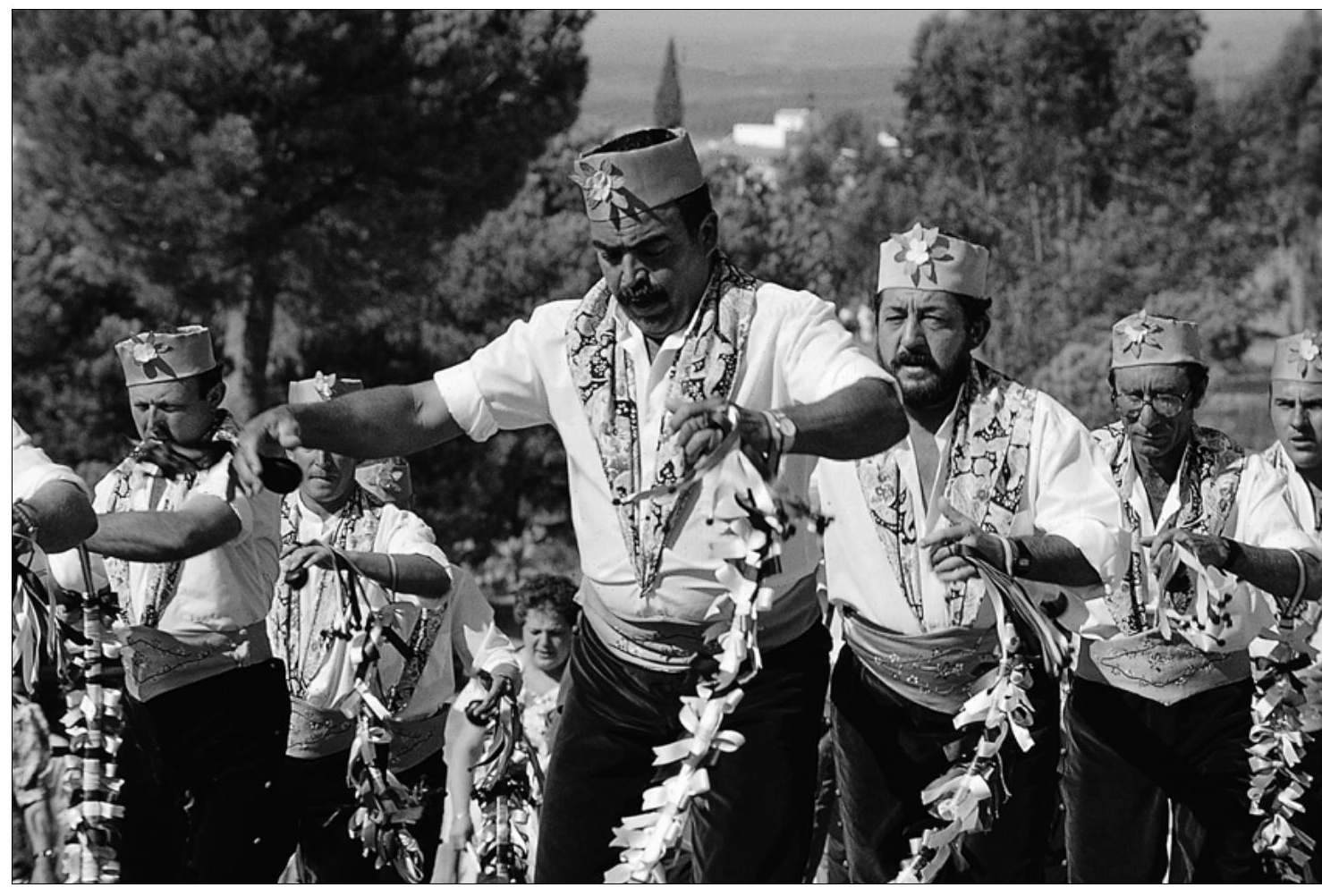

\title{
Antropología y Patrimonio Etnológico
}

Elodia Hernández León

Antropóloga

Centro de Documentación del IAPH

\section{A MODO DE PRESENTACIÓN: ANTROPOLOGÍA}

Y PATRIMONIO ETNOLÓGICO

Este boletín dedicado al patrimonio etnológico, no pretende ser una delimitación de la "parcela" patrimonial que corresponde a estos profesionales. No hay una intención de fijar que bienes son etnológicos, diferenciables del resto, y por tanto competencia exclusiva de antropólogos. Como se podrá leer en los textos que siguen, las reflexiones aquí recogidas tienen una vocación globalizadora, superadora de las sesgadas visiones disciplinares y objetuales del patrimonio que han marcado algunas líneas de trabajo hasta hace pocos años.

Sí es cierto que en los artículos hay una crítica a la ausencia de la antropología en las iniciativas relacionadas con la gestión del Pa- 
trimonio Histórico. Esta ausencia se hace más evidente a medida que en las publicaciones y debates sobre el patrimonio se alude a la identidad cultural, al contexto socioeconómico, al entorno cultural, al territorio, conceptos que son usados y analizados por esta disciplina.

Hay varias cuestiones que podemos relacionar con la ausencia de los antropólogos en el ámbito patrimonial, tal y como señalan estos textos. De un lado, el hecho de circunscribir la gestión patrimonial a bienes aislados, supuestamente dotados de valor en sí mismos, valor legitimado por la historia, ha supuesto una indiferencia hacia el patrimonio "más modesto". A ello se añade la infravaloración que ha sufrido cuando se le ha tenido en cuenta: el "otro" patrimonio, el denominado popular, se ha definido en negativo, por oposición a la producción culta, a la obra de los grandes maestros. En el caso de la arquitectura por ejemplo, frente a la arquitectura culta, a la de los monumentos, se ha descrito una arquitectura popular que aparece descrita como producto de un burdo funcionalismo, de malas copias de los modelos cultos, o dotada una ingenua belleza derivada de la falta de recursos: "El despojamiento de casi todo lo no estrictamente necesario le confiere unas condiciones de sobriedad y elegancia a la que el arquitecto popular difíilmente accedería teniendo a su alcance una mayor riqueza de posibilidades" (Carlos Flores 1976:20'). Esta definición de tipos contrapuestos, además de traducir una determinada ideología, ha añadido al estudio de los bienes culturales una dificultad considerable ya que lo culto y lo popular forman partes integrantes de un mismo sistema. Así diferentes autores al estudiar las haciendas de olivar ${ }^{2}$ y observar en estos conjuntos zonas muy "nobles" de gran riqueza junto a zonas "modestas" de gran "simpleza", dedican parte de sus esfuerzos a definir si son expresiones de arquitectura popular o culta.

Hoy, si revisamos los debates y publicaciones más recientes, observamos como la definición restrictiva del patrimonio y el abuso de las tesis dualistas están prácticamente superadas 3 . Sin embargo, conviene que no perdamos de vista estas consideraciones recientes y definamos una nueva metodología que destierre por completo el peso que aún tienen las valoraciones "clásicas" sobre los bienes "verdaderamente" importantes y prioritarios para la gestión patrimonial.

Por otro lado, se reconoce ${ }^{4}$ en estos artículos que en la ausencia de los antropólogos ha influido también la actitud de éstos. La necesidad de revalorizar como ciencia la antropología y el peligro de adulteración que podría suponer realizar tareas "aplicadas", es decir, desarrollar proyectos de intervención, hizo concentrar los esfuerzos en la investigación científica, sin mostrar una excesiva preocupación por el desarrollo de proyectos en el ámbito de gestión del patrimonio histórico, limitándose la presencia de estos profesionales al área de museos. Sin embargo, esta tendencia va retrocediendo, actualmente es cada vez mayor el interés tomado por los antropólogos en las iniciativas de gestión de nuestro patrimonio (ya sea desde la investigación, formación o difusión).
La tardía incorporación de los antropólogos a la mayoría de las instituciones de tutela patrimonial, no significa que "aterricen" con una visión carente de vigencia, antes al contrario, como se podrá leer en las páginas siguientes se aboga por una definición integrada e integradora del patrimonio, por olvidar la consideración aislada de los bienes patrimoniales para tener en cuenta el contexto cultural donde se han producido, reproducido o desaparecido, en definitiva compartiendo y aportando riqueza a las últimas tendencias abiertas en el terreno del Patrimonio Histórico.

En este sentido quisiera destacar cómo la antropología puede aportar herramientas para la tan necesaria aproximación al entorno sociocultural del bien patrimonial. La relevancia e interés de un bien se ha de establecer desde el análisis de su significación cultural, de su carácter diferenciador y representativo de la sociedad donde se integra. Es necesario reconocer el uso social del bien a lo largo del tiempo, el significado que tiene en el grupo social que lo habita o posee, para buscar y dinamizar soluciones creativas que procuren su conservación 5 .

Para elaborar este número, que pretende ser el inicio de una presencia continua del patrimonio etnológico y de la antropología en esta publicación, hemos querido contar con profesionales que trabajan en diferentes proyectos sobre el patrimonio de interés etnológico en Andalucía. Lógicamente no están todos los que son, pero si son especialmente representativos por su trayectoria, los profesionales que han colaborado en la gestación de esta publicación. Al incluir cada una de las colaboraciones hemos tenido la intención de abordar distintas temáticas para presentar una publicación de mayor riqueza. Quisimos contar con un artículo de carácter general, en el que Juan Agudo planteara cuestiones acerca de la definición y objetivos del patrimonio etnológico. Pensamos también que sería necesario contemplar los museos etnográficos, colaboración realizada por Esther Fernández de Paz. Centrándonos algo más, nos pareció interesante pedir a Pedro Cantero algunas consideraciones sobre la investigación que había realizado (Arquitectura del agua en la Provincia de Sevilla). Queriendo concretar aún más, pedimos a Carmen Guerra que reflexionara sobre uso social del espacio y arquitectura, tomando algún bien cultural como ejemplo. Agradecemos la buena disposición, sensibilidad e interés que han mostrado.

El debate sobre la protección del patrimonio etnológico, se ha recreado en la especificidad de éste, en que su protección puede ser "involutiva", contraria a toda dinámica cultural6, argumentando además que la gran amplitud del patrimonio etnológico la hace insostenible. Afirmaciones que pueden ser relativizadas si tenemos en cuenta que estos planteamientos no son exclusivos de la antropología, sino que otros profesionales relacionados con el patrimonio también están en continua reflexión y redefinición sobre qué debe ser protegido, cuál es el objeto de la gestión y cuáles deben ser los criterios de investigación, documentación, conservación-restauración y difusión......Habría entonces que definir y adecuar una metodología para la gestión del patrimonio a cargo de profesionales antropólogos que no despreciaran la mirada globa- 
lizadora propia de la antropología, ni tampoco la experiencia de otras áreas o disciplinas, trabajando con una actitud integradora.

\section{El Área de etnología en el IAPH}

El Centro de Documentación del Patrimonio Históri$\mathrm{co}$, una de las cinco áreas funcionales del IAPH, elabora productos que no sólo sirven a la administración jurídica sino que son instrumentos de conocimiento e información de los bienes culturales, destinados a entidades públicas y privadas, a investigadores y al usuario en general.

El Área de Desarrollo de la Información del Centro de documentación del IAPH, encargada de la selección y tratamiento de la información, cuenta con la colaboración de un profesional para el área sectorial de patrimonio etnológico que trabaja en el establecimiento de criterios para la selección e inclusión de información y la normalización terminológica.

Hasta la puesta en marcha del inventario de la $D G B C$, cada vez que se ha iniciado una labor de investigación o inventariado de bienes de interés etnológicos se ha partido de cero. En consecuencia además de existir una multiplicación de esfuerzos, nos encontramos con una gran heterogeneidad de resultados, lo que que dificulta su utilización como fuente documental. De esta forma, el objetivo primero del área sectorial de etnología es el diseño de un instrumento útil que partiendo de los inventarios existentes aglutine y sistematice la información, pudiendo una vez desarrollado, servir de punto de partida para las diferentes investigaciones e intervenciones en nuestro patrimonio etnológico.

Este objetivo está relacionado con la elaboración de un primer sistema informático integrado que se está llevando a cabo en el Centro de Documentación. Así la nueva aplicación sectorial de patrimonio etnológico, nace con vocación integradora, teniendo en cuenta las otras aplicaciones temáticas más avanzadas, para poder acordar puntos en común y específicos de cada especialidad.

La integración disciplinar ha quedado manifiesta también con la realización del Tesauro del Patrimonio Histórico. Este proyecto, que supone la elaboración de un lenguaje común de indización de los diferentes sistemas temáticos, está exigiendo un gran esfuerzo por parte del equipo de profesionales (entre ellos antropólogos) y la superación de las visiones disciplinares para poder hacer realidad el proyecto.

Con el cumplimiento de los objetivos propuestos y la progresiva incorporación del área de etnología a nuevos proyectos, esperamos que ésta sea una realidad consolidada, permanente e indisoluble del macro proyecto que constituye el Centro de Documentación del IAPH.
I. Carlos Flores: "Arquitectura popular en Andalucía" en Arquitectura popular española. Tomo IV, Madrid.

2. Por ejemplo: 198। RONQUILLO PÉREZ, R en Las haciendas de olivar en el Aljarafe Alto; 1992 AGUILAR GARCÍA, M.C. Las haciendas. Arquitectura culta en le olivar de Sevilla.

3. Así la propia legislación ha recogido una visión más amplia superando el carácter historicista: la ley de 199| del Patrimonio Histórico de Andalucía recoge en el título VII, artículo 61: "Forman parte del patrimonio etnográfico andaluz, los lugares, bienes y actividades que alberguen o constituyan formas relevantes de expresión de la cultura y modos de vida propios del pueblo andaluz'

4. Véase el articulo de Esther Fernández de Paz.

5. Durante la realización del estudio etnográfico: "Inventario de las edificaciones agropecuarias en El Parque natural de la Sierra Norte de Sevilla" comprobé una vez más, como las medidas coercitivas, el intento de congelación-conservación de algunos "monumentos" y del medio natural, habían producido una actitud de rechazo y no de valoración de los recursos naturales y culturales que poseía el territorio. A la larga estas intervenciones conservacionistas supondrán la pérdida de gran parte del patrimonio que se ocultará a los ojos de la Administración.

6. Juan Agudo reflexiona en su artículo sobre si proteger supone ir en contra de toda dinámica cultural y nos plantea como "no hay, sin embargo, objeciones a las crecientes dificultades que para el desarrollo y reproducción de estas mismas manifestaciones culturales nos estamos encontrando en los nuevos modelos de espacios arquitectónicos, organización de las actividades productivas, potenciación de modelos de ocio altamente consumistas, etc" 